Maximilian Hoor

\title{
The bicycle as a symbol of lifestyle, status and distinction. A cultural studies analysis of urban cycling (sub)cultures in Berlin
}

Journal article | Accepted manuscript (Postprint)

This version is available at https://doi.org/10.14279/depositonce-11212

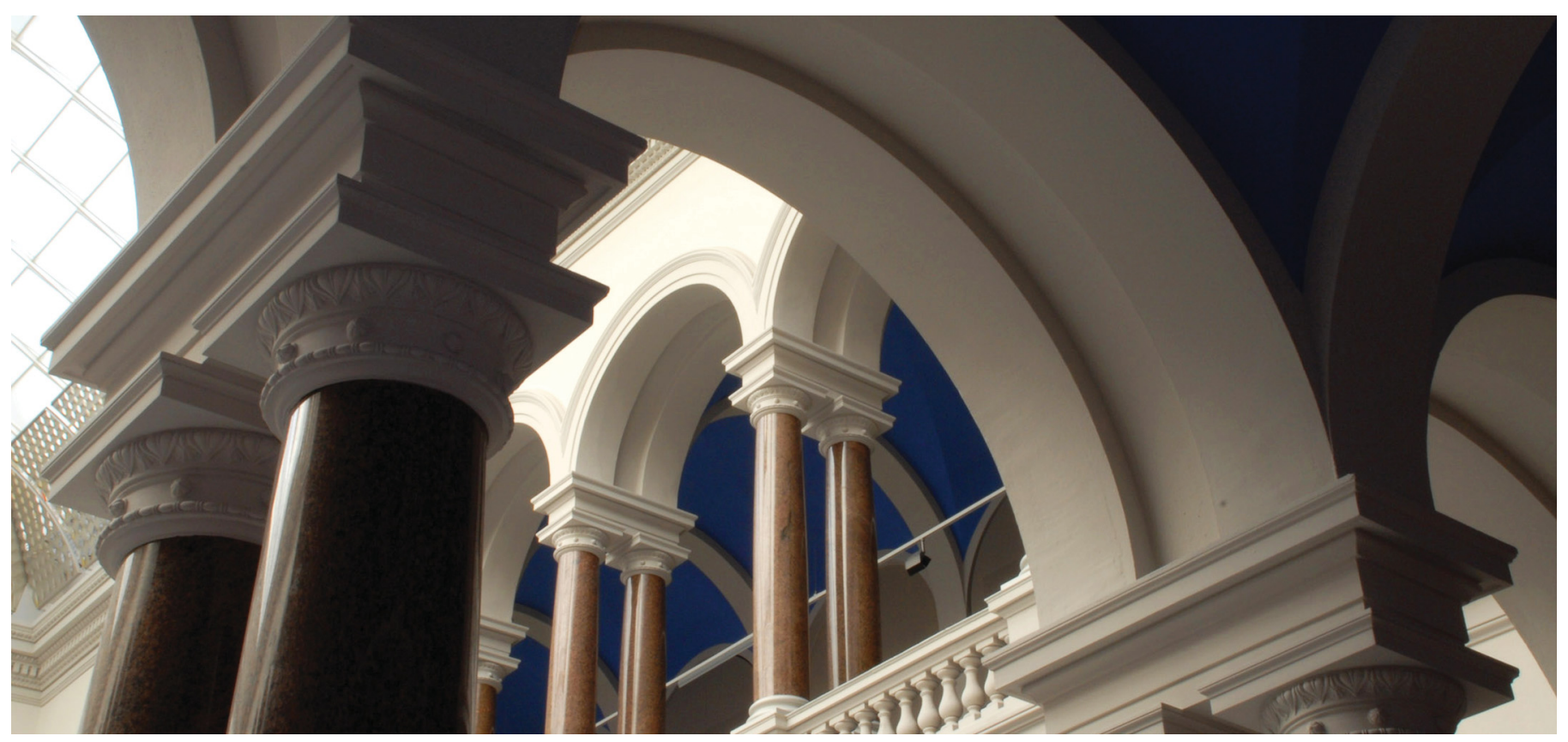

Hoor, M. (2020). The bicycle as a symbol of lifestyle, status and distinction. A cultural studies analysis of urban cycling (sub)cultures in Berlin. Applied Mobilities, 1-18.

https://doi.org/10.1080/23800127.2020.1847396 


\section{The Bicycle as a Symbol of Lifestyle, Status and Distinction. A Cultural Studies Analysis of Urban Cycling (Sub)Cultures in Berlin}

\section{Maximilian Hoor}

Chair of Integrated Transport Planning, Technische Universität Berlin, Germany

Maximilian Hoor, M.A.

Technische Universität Berlin

Faculty V - Mechanical and Transport Engineering

Institute of Land and Sea Transport Systems

Chair of Integrated Transport Planning

Secretariat SG 4, Room SG 4.1 407

Salzufer 17-19, 10587 Berlin

Germany

Phone $+49(0) 3031475229$

Fax $+49(0) 3031427875$

m.hoor@tu-berlin.de

www.ivp.tu-berlin.de 


\section{The Bicycle as a Symbol of Lifestyle, Status and Distinction. A Cultural Studies Analysis of Urban Cycling (Sub)Cultures in Berlin}

The bicycle has been gaining attention in planning, politics, academia and across the media and has become increasingly present in urban landscapes and popular cultures: young urbanites ride minimalistic, stylish and individualised bicycles and wear messenger bags for their commute to work or to university.

Additionally, bicycles can be seen in lifestyle blogs, advertising, shop windows or living rooms as decoration and eye-catchers. Taking this observation as a starting point, I focus my research on how bicycles, especially fixed-gear bikes and recent cycling trends are being used to express lifestyle, status, and social distinction in an urban middleclass context. In order to investigate further, I conducted a cultural studies analysis based on participant observations and media analysis exploring cultural meanings and practices in urban cycling cultures in Berlin, Germany. My research leads me to the result that the bicycle is increasingly turning into a key object of popular urban culture, combining tendencies of commercialisation, specialisation and standardisation, with a strong focus on aesthetics, design, lifestyle and consumerism. In the context of urban cultures, the bicycle is therefore experiencing a symbolic revaluation, making it desirable to more and more urbanites, but also more exclusive.

Keywords: Urban Cycling; Cycling Cultures; Cultural Studies; Consumer Cultures; Lifestyle; Fixed-Gear Bicycles 


\section{Introduction}

As the bicycle gains attention in planning, politics, academia and media, it is also becoming more visible in urban landscapes and popular cultures: young urbanites ride minimalistic, stylish and individualised bicycles and wear messenger bags. Additionally, bicycles can be seen in lifestyle blogs, advertising, shop windows or living rooms, functioning as decoration and fashionable eye-catchers.

While the bicycle is one of the most simple and minimalistic forms of transportation there is, it is also a highly developed, diverse and individualised object that caters to many different users, whose diversity is not be underestimated (cf. Cox 2019, 2015; Hutchinson 2017; Smethurst 2015; Vivanco 2013). Along with this diversity, tiny distinctions in material, practices and symbols become important. This means there are huge subcultural and symbolic differences, for example when considering whether a bike comes with several gears (normal road bike) or without gears (single-speed or fixed-gear). It may all look pretty much the same to an outsider, for cyclists who identify with either of the related scenes, the specific distinction means the world. Following this internal logic, in a city like Berlin, the multitude of bikerelated scenes and their respective practices and representations become relevant for the bicycle's recent overall symbolical revaluation in terms of lifestyle, status and distinction for the young, sporty and hip.

Some academics question whether following the trends set by highly individualised scenes may threaten a city's attempt at working towards more social inclusiveness and mobility justice, and rather reinforces (white) male dominance and urban gentrification. The fixed-gear bicycle, especially, is relevant in this respect as it is stereotypically framed as an indicator of late-modern capitalism, hipsterism and gentrification (cf. Stehlin 2019). However, many discussions on fixed-gear cycling seem rather cursory, and lack a deeper investigation and understanding of the fixed-gear 
bike, its related subcultures and its wider cross-connections. As Zach Furness has stated (2010: 169): "These trends [fixed-gear cycling] seem to play a substantive role in getting more people interested in biking overall, which is an achievement unto itself, and one that speaks to the profound role that culture plays in the reproduction of transportation norms.“

Further investigating this role of urban cycling cultures, my research indicates that less tangible developments in lifestyle, hobby and amateur sports cycling-which by numbers do not seem to be the most relevant aspects of cycling per se (cf. Borgstedt et al. 2019) — are especially relevant for the bicycle's recent symbolical revaluation to become an object of lifestyle, status and social distinction based on an increasing symbolical capital. In terms of creating sustainable mobility cultures - which require a fundamental cultural renegotiation of existing structures, beliefs, lifestyles and identities - this becomes relevant not only for the cultural and social sciences, but especially for transport planning, policy-making and cycling promotion (cf. Hoor 2020, also Chap. 5).

To explore this, I used a cultural studies approach, together with methods of participant observation and media analysis on local cycling cultures-taking fixed-gear bicycles as a starting point—in Berlin, Germany. For several years, I followed the actors and the vast diversity behind the scenes, which led me from bike messengers to hipsters; from fixed-gear-criteriums to gravel rides; from subcultural style to fashion and advertising; from local manufacturers to multinational companies (Chap. 4). My research is grounded in my own explorative observations, understanding and interpretations of the field and therefore highly particular and subjective, aiming not for objective truth, but for specific reading of cultural phenomena (see Chap. 3). 
Drawing on theories from cultural studies, consumer cultures, cultural sociology, social psychology, mobility and transport studies (Chap. 2), I have focused on the following questions: how are bicycles (especially fixed-gear bikes), as well as accessories and clothing being used within an urban context to express lifestyle, status and distinction? Which practices and meanings of urban cycling go along with this? How is this represented in urban cycling scenes, the bicycle industry, media representations and fashion? How does this effect the symbolic meaning of urban cycling cultures and what consequences might this have?

\section{Theoretical Framework}

The use of bicycles in cities can be explained by considering factors such as infrastructure, costs, urban density, distances, weather or topography, but it also depends on (perceived) safety, as well as on attitudes and perceptions prevalent in given society towards cycling (cf. Heinen et al. 2010).

Most of the factors listed above address a rational choice model—assuming people take the quickest, cheapest, safest or most comfortable way to get from A to B. In contrast, social psychology research reveals that these perceived instrumental motives are highly subjective and vary significantly between situations and individuals. Additionally, the research shows that affective and symbolic motives are also largely relevant for specific transport choices (cf. Gatersleben 2013; Steg et al. 2001). Affective motives describe emotions like stress, effort, excitement or joy associated with or caused by the use of certain means of transport. In contrast, symbolic motives address distinction and identification that are linked with sociocultural attributions. For example, the car is widely seen as an object of distinction that allows freedom and individual mobility while also representing one's wealth and status. The car thus has a 
strong cultural significance for people's everyday ways of life and the functioning of our society, culturally (re)producing its own hegemony (cf. Manderscheid 2014; Urry 2004)

Similar to cars, bicycles and bicycling have different cultural meanings that depend on place and time. For example, at the end of 19th century the bicycle was used by the European bourgeoisie as an object of distinction and fun, before being massproduced and losing the distinctive quality of its former scarcity (cf. Lessing 2017; Hutchinson 2017). When mass motorization took over, the bicycle was largely forgotten and mainly seen as a sports object, children's toy or a subcultural tool for social critique, e.g. for punks, provos and environmental activists (cf. Vivanco 2013; Furness 2010; Horton 2009). Today you can find similar variations in its meaning: in an African, Asian and South American context it is often stigmatized as a transport mode of the poor, while in traditional bike cities such as Amsterdam and Copenhagen, the bicycle is a factual and normalised part of everyday life, while in other urban areas in the post-industrial world, it is once again becoming a signifier of wealth, identity and status (cf. Smethurst 2015; Vicanco 2013; Horton \& Parkin 2012).

Dave Horton et al. $(2007,7)$ argue: "Cycling takes place in public space, subject to the public gaze (...) Both the bicycle and the act of riding a bicycle unavoidably convey status. This status is never fixed, varying greatly according to time and place, and depending on attitudes held by both the rider and observer. Sometimes cycling conveys high status; sometimes it is stigmatised; sometimes it depends on what the person riding looks like, what they wear and the machine they ride." These status attributions, especially the latter (rider, appearance, bicycle) rest upon a complex system of cultural figurations where even "the most mundane objects $(\ldots)$ take on a symbolic dimension" (Hebdige 1979, 2). These objects and assemblages are ambiguous and open to subjective interpretation. Still they act as symbols of membership and distinction to 
various lifestyles and social groups and normally go along with certain practices and competences (Bourdieu 1984).

Consumer behavior, such as the use of fashion and accessories, serves to express meaning, style and distinction, and is based on an interplay between individual imitation and demarcation, on social equalisation and differentiation: "It unites those of a social class and segregates them from others. The elite initiates a fashion and, when the mass imitates it in an effort to obliterate the external distinctions of class, abandons it for a newer mode - a process that quickens with the increase of wealth" (Simmel 1957, 541). Therefore, style becomes necessary to expressing individuality and one's own self by using objects and symbols, as well as certain bodily practices for a wider part of society. Any consumption then-just like the use of bicycles or related accessories and clothing - can be conceptualised as an idealistic and symbolic practice which inherently constructs meaning and social differentiation by using codes, signs and objects which are not only significantly different from each other, but also show status and identification in a social hierarchy (Baudrillard 1968).

In this sense, certain objects and bodily practices, as well as combinations of these might act as symbols of lifestyle, status and distinction, which express meaning, identification and social position (Bourdieu 1984; Goffman 1951). Furthermore, they demarcate social boundaries while homogenising the members belonging to one group (Simmel 1957). Status symbols are context-specific and do not work for themselves, meaning they have to be used in skillful ways (Bourdieu 1984; Goffman 1951).

In the tradition of cultural studies, subcultures are described as distinctive lifestyle groups that strive towards an alternative way of living. Bricolage of style, rituals and symbolic objects is used to form unity within the group and show differentiating values and attitudes towards others (cf. Gelder and Thornton 1997). 
However, subcultural values like creative and playful self-expression, stylisation of individualistic and sacred objects or the focus on pleasure, have become values of $21 \mathrm{st}$ century consumer cultures based on flexible consumption and self-entrepreneurship (Schiermer 2013; Greif 2010; Featherstone 2007; Muggleton 2000).

\section{Research Design and Methodology}

As urban cycling cultures are shaped and (re)produced both in the virtual realm of printed/digital media and on the lived-streets, an investigation must consider both. I conducted a cultural studies analysis, based on participant observations, ethnographic interviews and media analysis taking place in urban cycling scenes in Berlin. Culture, understood as a way of life and a system of meaning, must therefore be uncovered, explained and deciphered by a profound cultural analysis (Williams 1961, 1981). For this reason, I opted for a consistently qualitative research design that aims to explore, understand, sensitize to and theorize on socio-cultural phenomena (cf. Lamnek 2010; Strauss and Corbin 1990). In the practice of my field research, this means meeting and talking with specific actors, witnessing certain events, learning actions and practices for myself or becoming familiar with different perspectives, meanings, images, narratives and objects (cf. Spradley 2016; Breidenstein et al. 2015; Denzin 2014; Hammersley and Atkinson 2007).

\section{Cultural Studies and Research Perspective}

Cultural studies are often referred as a quite unorthodox way of academic research, eclectically using research methods and theories from various disciplines, having an inter- and transdisciplinary research focus. Additionally, cultural studies are often politically driven, deriving from the researchers being involved in the field under investigation themselves, not aiming for academic objectivity, but for setting political 
agenda and producing popular readings of cultural phenomenon (Lindner 2010; Grossberg et al. 1992).

Following this approach, my research work is characterized by a strong integration of myself into the research context. This personal involvement provides me with a direct proximity and access to objects and subjects of investigation, as well as a profound understanding and an insider perspective on the phenomena under investigation. Therefore, I may be able to evaluate, contextualise, supplement and validate the investigated phenomena and developments accordingly. On the other hand, it also leads to the assumption that I myself am too close as a scientific observer and may have lost the academic distance to the object of investigation - the so-called "going native" as it is often called in ethnographic research.

However, applying a social constructivist understanding of science onto ethnographic and cultural studies research itself—a concept known as "crisis of representation"—requires a deliberate departure from the idea that any ethnographic text would represent a realistic representation of an existing reality. Accordingly, ethnographic descriptions are themselves understood as interpretive translations of a reality, constructed in a situational, particular and context-specific way-they are narrative constructs themselves (cf. Lindner 2010; Clifford and Marcus 1986).

\section{Biography and Participant Observation}

I initially started my research on urban cycling cultures for my Master's thesis in 2014, and have been continuously working on it as a researcher and practitioner since. After finishing my studies in human geography, I started working within the cycling industry and became a bicycle advocate myself. I became an early member of the Volksentscheid Fahrrad which later co-initiated Berlin's mobility law and expanded their activities 
across Germany. ${ }^{1}$ Simultaneously, I joined the team of Radbahn Berlin ${ }^{2}$, another wellknown cycling and urban development project in Berlin that I am still affiliated with today as board member of its supporting association and managing director of one of its projects. I then fully committed to my academic perspective on the field when I started the doctoral research position at TU Berlin in 2016.

For my research I then co-used and rehashed field contacts and (re)started participant observations such as taking part in bike-centered events, getting into different cycling scenes, watching local races and bike-polo tournaments, visiting meeting points like trade shows and bicycle shops as well as riding the city and its surroundings on my own (everyday commuting and recreational) and in sportive group rides, using all kinds of bicycles (see Figure 1).

\section{Figure 1: Table of shows, events and races attended as participant observer (all events located in Berlin, unless stated otherwise)}

[Figure 1 near here]

Over the course of five years, I became an insider on more and more levels: bicycle advocacy, everyday commuting, fixed-gear-scene, road biking and, most recently, gravel biking. ${ }^{3}$ I ditched my old bike and got myself several new, stylish and

\footnotetext{
${ }^{1}$ See https://volksentscheid-fahrrad.de/en/3550-2/ for further information

${ }^{2}$ See https://radbahn.berlin/en

${ }^{3}$ Gravel biking is probably the hottest trend for urban bikers in Berlin at the moment - as one participant said: "Everyone rides gravel now". Simply put, it is a mixture of mountainbiking and road cycling. Gravel biking evolved within the last ten years in the United
} 
more serious bikes for commuting and sports. My style of clothing changed, as well as my level of fitness and bike handling skills. This change in material and competences was due to several reasons, firstly, as a necessity to do group rides with more advanced and experienced riders and to fit in; secondly, to fully embrace my research and be part of different cycling scenes, physically as well as culturally; thirdly, because I also had friends who were more experienced than me and participated in cycling events and races: they shared their know-how with me or even gave me their old outfits; fourthly, and probably most importantly, because my own identification, lifestyle, relation and understanding of cycling changed during the participation.

Consequently, I met dozens of other affiliated people, read numerous books, blogs and media articles and watched countless videos on content-sharing platforms and followed a large variety of locally and (inter)nationally popular cyclists in different fields on social media, adding the virtual realm in online media to my research.

\section{The Case Study of Berlin}

In Germany, the importance of cycling as a mode of transport has increased significantly over the past 15 years and is still becoming more and more popular. This is especially true for cities and metropolises and for a younger generation. Within a sociocultural field, the more progressive and affluent social milieus—young urbanities focusing on consumerism and style as well as individualism and non-conformism — are the ones in which the bicycle is the most present (cf. Nobis 2019; Borgstedt et al. 2019).

Berlin, from an outside perspective, often has the public image of a rather cycling-friendly city. However, while the cycling share has increased significantly in

States and is currently booming, with a huge rise in gravel-events and participation (King 2020). 
recent years - especially in some inner-city areas - cycling-related infrastructure and services have not been expanded accordingly and cycling growth has little to do with governmental interventions (cf. von Schneidemesser et al. 2018; Sheldrick et al. 2016). Still, Berlin has a very vivid cycling culture, with hundreds of cycling shops, wellknown trade fairs, races and ambitious cycling initiatives. Due to the vast work and promotion of cycling initiatives, the city is now facing a large-scale infrastructural transformation, which has been politically agreed on in Berlin's new mobility law in 2018 (cf. MobG BE 2018).

As already stated, instead of focusing on these relevant structural policy changes and the political cycling scene itself - and e.g. investigating the role of cycling initiatives, campaigning and participation — this article focusses on the less tangible symbolical revaluation of the bicycle in terms of lifestyle, status and social distinction that is visible in the context of more sportive and lifestyle-based urban cycling scene in Berlin.

\section{Urban Cycling (Sub)Cultures and its Representation in Bike Industry, Events and Meeting Points, Rituals, Bicycling Practices, Media, Fashion and Consumer Cultures}

"Many cyclists literally bought into this consumer identity by using bicycles and bicycle accessories to signify their participation in a modern popular culture." - Zack Furness 2010, 19

While this statement to me sounds like a critical synopsis of today's urban cycling culture, it actually refers to the role of the bicycle for the European bourgeoisie in the 1890s. Taking a broader look at bicycling cultures in Berlin today, I found very similar characteristics in quite different fields and outcomes, showing a focus on aesthetics, 
lifestyle, consumerism and a specific urban functionality and design that seems to be (again) new to cycling.

The Fixed-Gear-Scene as a Starting Point: From Messenger Lifestyle to Hipsters and Popular Culture

Figure 2: A Brief Evolution of the Fixed-Gear onto Urban Roads and Popular Culture

[Figure 2 near here]

Although the first safety bicycles in the late 19th century were fixed gears as well, today's fixed-gear bikes ${ }^{4}$ originate from track bikes, which have to be light, compact, aerodynamic, safe and agile for races in the velodrome. This type of bicycle can thus be considered the "antithesis of utilitarian transportation" (Furness 2010, 162), which might explain why it was uncommon for use on urban streets for a long time. Then, in the late 1970s, things changed: "Back then, track bikes took over. If it wasn't a fixed gear, [it was] a road bike turned fixed (...). They were faster and easier to maneuver in traffic, it was easier to brake with your legs than your hands. I think the whole community adapted to track bikes" (as cited in Edwards and Leonard 2009, 66), reports a former messenger from New York. Fixed-gear bikes were cheap, light, fast, and easy to maintain, and had no extra parts that could be stolen.

\footnotetext{
${ }^{4} \mathrm{~A}$ fixed-gear bike is a bicycle whose main feature is simplicity. It has only one gear with no freewheel mechanism, forcing riders to constantly keep pedalling while riding. This also enables riders to slow down or bring their bike to a halt by pushing back with every rotation, or by fully blocking the back wheel. Fixed-gears can thus function without brakes. The single-speed bicycle is a hybrid that combines the minimalistic aesthetics of the fixed-gear with the comfort of a free wheel and thus requires brakes. Both types have become icons of urban cycling today and are often mistaken for each other.
} 
However, besides these practical issues, riding brakeless in dense urban traffic presents a symbolic statement in and of itself: riders show their skills, power, fearlessness and deviant attitude. Additionally, all clothing, items and accessories both fulfil a certain functionality - the messenger bag is necessary for safely carrying packages - as well as an inherent symbolic function and compensation: it is a sign showing one's status, work and lifestyle as a bicycle messenger. Although many messengers also use different types of bicycles and do not participate in the messengerlifestyle at all, the fixed-gear bicycle, together with certain clothing and style of riding contributes centrally to the construction of messenger-identity and style (cf. Kidder 2011; Furness 2010; Fincham 2006).

Kevin Wehr $(2009,109)$ labels bicycle messengers as "The Last Non Co-Opted Punk Rock Subculture", which might have changed fundamentally in recent years. Before popular culture took hold of fixed-gear bicycles and the mentioned accessories of messenger style, these were used almost exclusively by bicycle messengers. One of the early groups of riders and film producers that took fixed-gear bikes and messenger style to a new level were Mash SF and Macaframa from the San Francisco Bay Area: "Mash pretty much kicked off everything... When the trailer first came out it was like it opened the doors for everyone" (as cited in Edwards \& Leonard 2009: 85). Riding brakeless down the steep streets of San Francisco, doing long skids, overtaking cars, doing wheelies and tricks: their videos are full of action, tricks, punk rock music and film aesthetics that are linked to other urban youth cultural productions in skateboarding or BMX. These fixed-gear riders could be described as "neoliberal rolemodels" similar to what Sebastian Schweer $(2014,167)$ calls the urban skateboard-scene, meandering "between urban rebellion and neoliberal self-design" (ibid., translation by author), 
between subcultural knowledge and marketing skills, between resistance and fun (cf. Eichler 2017; Potter 2010).

Since the early 2000s, fixed-gear bikes have slowly gained access to urban popular cultures. Mark Greif $(2010,138)$ writes about hipsters: "The fixed-gear bike now ranks as the second-most-visible marker of hip"-next to slim-fit jeans. Hipsters adopt symbols, practices and insignia of the messenger subculture in order to show off and gain distinction, so that ,the fixed-gear bike has become a trendy icon of urban coolness“ (ibid., 162). Moreover, this very process made fixed-gear bikes and messenger style commercially relevant for a bigger part of society and consumer culture.

The hipster ${ }^{5}$ is the uppermost form of an aesthetic consumer, using techniques of imitation and demarcation, of irony and pastiche. While acting within boundaries of consumer society they are looking for the right object, assemblage or practice to gain distinction. They then act as visible urban trendsetters and early adopters, and most likely work in cultural and media production themselves, functioning as cultural intermediaries, bridging the gap between cultural production and economic valorization, between consumers, producers and distributors of symbolic meanings (cf. Schiermer 2013; Greif 2010; Featherstone 2007).

"The fact that bicycling is even remotely considered fashionable and hip in certain U.S. cities is hardly an insignificant achievement given the profound challenges facing those who simply attempt to alter, let alone transform, the dominant cultural norms and everyday habits associated with transportation. The popularity of fixed-gear bikes is not exclusively responsible for this development, but it has unquestionably focused more attention on urban cycling and is arguably instrumental in cultivating a different image and aesthetics that many now associate with bicycle transportation. Less obvious, perhaps, is the influence this once marginal and/or subcultural trend exerted on the bicycle industry in recent years." - Zack Furness 2010, 167

\footnotetext{
${ }^{5}$ Following Greif (2010) the hipster functions as a general term for young, mainly white and male, fashion-conscious urbanites, based on cultural attribution.
} 


\section{Bike Industry: Commercialisation and Aesthetisation of a Minimalistic Design}

The popularisation of the fixed-gear bicycle is not only visible in urban popular cultures, but got hold of consumer cultures and the bicycle industry. There is a completely new segment, often called urban bicycles, which combine the functional requirements of a commuter bicycle with the aesthetics of a one-gear bike, allowing flexibility and comfort with only little impact on the minimalistic design.

I found the cultural basis for this development grounded in cycling shops and manufacturers that came up in Europe and North America over the last decade, such as Standert Bicycles, 8bar or Schindelhauer in Berlin. These brands often started out by producing track bikes and single-speed urban commuting bikes that are customised or handmade. Most brands then extended their range towards more expensive sportive bikes (especially road and gravel). Prices are in the higher segment starting from around 1,000 EUR for a simple urban single-speed bike and go up to 5,000 EUR for a sport bike.

Additionally, the people working at these shops tend to have a strong affiliation with the urban cycling scene themselves, often have a background as bicycle messengers or started fixed-gear riding many years ago. There seems to be a very strong personal identification with the products for sale. Most shops additionally have racing teams (Team Standert, 8bar Team, Team Schindelhauer-Gates) which take part in local as well as international fixed-gear races like the RadRace series or the Red Hook Crit as well as local and regional road races, cyclo-cross and gravel events.

Much less rooted in urban subcultures, multinational companies like Amazon or Walmart, as well as bicycle and outdoor chain stores (e.g. Decathlon), also started to produce and sell cheap single-speed and fixed-gear bicycles. Additionally, a similar aesthetic development can be observed in the segment of pedelecs, which is very 
successful in Germany especially among middle-aged and older people (cf. Nobis 2019, Borgstedt et al. 2019). While there are electric assistances in all kinds of bicycles, within the last years more and more producers have started up and created pedelecs for urban consumers who value the minimalistic aesthetics and functional design of onegear bikes, which normally come with a hidden engine and battery as well as gear hubs and hub dynamos. ${ }^{6}$

\section{Symbolical Meanings: Accessories focusing on Lifestyles and Aesthetics}

Many innovations are introduced to the bicycle industry via blogs or magazines, at trade fairs and exhibitions. Some of those innovations show a focus on minimalist aesthetics, urban lifestyle and design rather than advanced technology. To illustrate this point, I am going to present an alternative reading on one bicycling accessories, that signifies this symbolic meaning in particular: wall mounts.

Wall mounts are one of many examples that show how the bicycle is being used and rebranded today as a lifestyle and fashion object. The most common places to park a bicycle are on the street, in the backyard, garage or basement. However, some people take their bicycles into their homes, where they place them in the hallway or even hang them like paintings on the wall. Several manufacturers from all over Europe and North America have quickly picked up on this niche trend and introduced minimalistic wall mounts which have the sole purpose of hanging a bike on the wall and turn it into an accessory for the home. ${ }^{7}$ This is indicative of an increasing esteem for the bicycle as an

\footnotetext{
${ }^{6}$ e.g. Coboc, Ampler, VanMoof, Geos Urban, Cowboy, HNF Heisneberg, Sushi Bikes, Asfalt LR, Schindelhauer.

${ }^{7}$ See https://itstartedwithafight.de/category/wandhalterungen/ for a collection of over 80 different types of bicycle wall holders.
} 
object in different ways: The bicycle is considered (1) valuable enough to carry it up the stairs or across the threshold into the home, (2) a decorative feature in one's personal environment, (3) an item worthy of protection and care that the backyard, basement or street do not provide and (4) it fulfills a certain prestigious function by occupying a space usually reserved for family photographs, artwork or posters—showing people's social status, identity and personal taste (cf. Bourdieu 1984).

\section{Events and Meeting Points: Bicycle Cafés and Trade Fairs}

Traditionally, bicycle shops sell bicycles, components, equipment or specialised clothes and offer professional advice, repairs and maintenance in an integrated workshop. In many metropolises bicycle shops now often have a different appearance, which makes them look more like a hipster café, boutique, bookstore or restaurant. Besides a traditional bicycle shop or repair-station, those cycling cafés serve food and beverages-such as artisan coffee, ice-cream, cakes and craft beer-offer working opportunities, meeting points, group rides, sports event livestreams or movie nights while selling cycling-related fashionable clothes, accessories and bicycles - the all-combining element being bicycles. ${ }^{8}$

In Berlin, there are many bicycling-related social events for different scenes, industries and subcultures: trade fairs, exhibitions, critical mass, bike rides, races, meeting points et cetera. While huge trade fairs such as Eurobike in Friedrichshafen or VELO Berlin focus on different aspects of ordinary cycling, the Berliner Fahrradschau was a lifestyle-based trade fair that took place annually from 2010 in Berlin and

\footnotetext{
${ }^{8}$ e.g. Standert, Keirin Cycling Culture Café, Steel Vintage Bikes or Cicli Berlinetta in Berlin; Look Mum No Hands, or former Lock 7 in London; Dosnoventa or Pavé Culture Cycliste in Barcelona or the several Rapha Clubhouses.
} 
expanded to Vienna in 2016, focusing on hip urban cycling cultures and featuring a wide range of events to coincide with the fair, such as bike-polo tournaments, alleycats, group rides, fixed-gear races and sprint events. Although the Berliner Fahrradschau was discontinued in 2018, new trade fairs such as kolektif berlin and Cyclingworld in Düsseldorf as well as more traditional VELO Berlin adapted more to their lifestyle- and fashion-based concept and more subcultural fringe events. ${ }^{9}$

\section{Events and Competition: Fixed-Gear-Criteriums}

While commercial "sportives", a certain type of hobby cycling event, in general have become more popular in road cycling (cf. Hutchinson 2017), subcultural based fixedgear races and criteriums have become popular as well. The most famous one is the Red Hook Crit which originated in Brooklyn in 2008, but has since also expanded to European cities (Milano, Barcelona, London). Although all their races were cancelled since 2019 and there is no sign of resumption yet, Red Hook is the main inspiration for a new kind of cycle racing, mainly focusing on track or road bike criteriums on urban courses, which feature a mixture of professional riders, messengers, amateur and hobby cyclists competing on a technical circuit.

The atmosphere of these events has more in common with punk rock concerts than with traditional sports events, featuring loud music, beers, smoky air and tattooed people. Many of the more subcultural riders ride rather run-down and stickered bikes, wearing normal street wear, while more ambitious riders and teams compete with carbon-everything track bikes and aerodynamic skinsuits. The event lends the rules

\footnotetext{
${ }^{9}$ Similar events in the UK would be Spin Cycling Festival in London and Birmingham BikeFest.
} 
from traditional track races and focuses on proximity to the spectators, live action and the party-like atmosphere, which draws a young and hip crowd. ${ }^{10}$

Fixed-gear races are quite different from more traditional road cycling races, as riding a fixed-gear requires a lot of technical skills, not only fast legs. For example, some very well-known former professional cyclists (such as olympia winners Fabian Cancellara and Callum Skinner) got dropped in the very early rounds of races from Red Hook and RadRace, just because they could not make it. While this is a rather new phenomena, those fixed-gear criteriums have started as a small subcultural scene being rooted in messenger and punk rock cultures only. While some of them still are, others were soon able to expand and have been commercialized with main sponsors, advertising boards, professional riders, thousands of spectators and even live-streaming coverage. ${ }^{11}$

However, things might have already changed and having talked to riders, it seems, that due to several reasons (e.g. the discontinuance of Red Hook as its flagship; the professionalisation of teams and riders - detaching the sport from its original subcultural scene; the costs and resources needed to organise the events, as well as sometimes difficult collaborations with more traditional cycling clubs and races) fixedgear criteriums in Germany have declined in numbers after their heydays within the last two years.

${ }^{10}$ e.g. RadRace and 8bar Crit in Germany; Thundercrit and London Nocturne in the UK, as well as a lot of races and criteriums in the Netherlands, Belgium, France, Italy and the U.S.

${ }^{11}$ The RadRace Last Man Standing in Berlin was live-streamed and commentated by British Global Cycling Network (GCN) reaching about 100000 views on top of about 10000 spectators at the venue. 


\section{Habitus, Bodily Practices and Consumption I: Cycling Etiquettes and Style}

In contrast to the previously discussed fixed-gear cycling with its deviant and somewhat punk-rock attitude, road cycling is much more posh. If you happen to stroll past the Standert Bicycles store or the Rapha Clubhouse in Berlin-Mitte on a weekend, you are likely to see people in very slim-fit lycra clothing sipping a flat white and eating cheesecake or a cinnamon bun with their road bikes parked next to them. For everyone not familiar with the scene, this may look weird, as most people would not showcase their sports outfits or head to a public café after a workout before at least taking a shower or changing into a post-workout outfit. However, this perceived clash of workout and leisure is no coincidence, but a rather planned and distinctive social practice, showing off athletic bodies, expensive bikes, fancy clothing and tons of specific signifying symbols after a group ride.

Following this observation, there is an endless number of implicit rules for how to ride and what to wear on and off the bike. It is about many factors such as certain brands, colors and combinations thereof ('all black' being one trend in recent years), a certain sock length, cultivated tan lines, shaved legs, the dos and don'ts of cycling caps or team kits, cycling habits (like holding the line and hand signals) as well as platitudes/attitudes such as 'harden the fuck up', 'it never gets easier, you just go faster' (cf. Velominati 2014).

Obviously, these etiquette rules do not have to be taken too seriously if you just want to ride your bicycle. But, if you want to be part of a specific cycling scene these are the major attributes of identification and the rules are often taken very seriously indeed. For example, in today's professional cycling sport, one major marketing slogan is "aero is everything", justifying riders to shave their legs and arms, to wear skintight cycling clothes, aero-helmets; use aerodynamic wheelsets, computers and framesets- 
everything can be aerodynamically improved in search for that extra "free speed" as Michael Hutchinson (2017) puts it. However, in the context of hobby and amateur athletes, who will quite likely never earn a penny riding their bikes, this otherwise rational and technical argumentation lacks persuasiveness. My hypothesis is, that all of the mentioned elements have a much stronger symbolical value, acting as symbols of membership to a specific cycling related lifestyle and community. To further illustrate this point, an acquaintance who recently decided to draw back from amateur road cycling, started re-growing his leg hair as a symbolic statement accompanying his exit from the sport.

Similar to what Sarah Thornton (1996) writes about the club-scene, also cyclists do have their own order of prestigious symbols and practices, but this sometimes change fundamentally within different scenes and contexts: Whereas you will be considered instagrammable and cool, if you show up at the world's most prestigious fixed-gear-criterium, casually riding your DIY-track-bike in your cut-off jeans and hoodie; you will need much more expensive materials and outfits to just to join a basic group ride by Rapha, Pas Normal Studios or alike, or you will simply feel out of place. Each cycling subculture has its own delicate differences, that out novice riders as rookies while strengthening the exclusivity of the inner scene, revealing someones real habitus within a particular cycling culture (cf. Cox 2015; Thornton 1995; Bourdieu 1984).

\section{Habitus, Bodily Practices and Consumption II: Fashion and Distinction}

When my own parents, upon visiting me in Berlin, saw me in what I would consider a well-fitting cycle jersey I had ordered online and was trying on, they immediately suggested that I needed to size up. It needed to be longer, it needed to be wider, this could only be a kid's jersey... little did they know! When thinking about road cycling, 
many people, such as my parents, think about MAMIL (Middle Aged Men in Lycra) who ride their expensive bikes in colourful, but often mismatching spandex. Today's road cycling culture seems to be fundamentally hipper and even more exclusive, which comes at a price: monetarily, but even more so culturally.

Connections between bicycling and fashion have existed since the earliest days of bicycling, for example in women's emancipation at the end of the 19th century (cf. Lessing 2017; Furness 2010). Today's connections between cycling and fashion, seem to be much deeper rooted in flexible accumulation and postmodern consumer cultures and show a combination of subcultural lifestyles and the creative industries. To illustrate my argument, I will draw upon bicycle fashion collections, which indicate that one of the most central concerns for urban cyclists today is how to look good on your bike.

In recent years many 'new' players from the US, Japan, Australia and Europe like Rapha, PEdALED, BBUC, Pas Normal Studios, POC, Attaquer, MAAP, Endless, Isadore or Cafe Du Cycliste have begun to institutionalise this niche of high-quality and lifestyle-based cycling apparel. Pas Normal Studios for example is owned by Danish fashion and lifestyle brand Wood Wood, with jerseys starting at around 200 Euros. Considering these prices — some road cyclists wear similar quality brands for every single item from shoe to helmet—just the outfit may easily be worth a second-hand car. An Australian researcher interprets these trends as a twenty-first century dandyism, being "part of a global trend that fuses sport, leisure and a lifestyle that means being fit and strong, while simultaneously exhibiting masculinity through sartorial choices." (Ferrero-Regis 2016, 95).

Rapha is arguably the leader in this development and is "as much a fashion brand as it is a performance road wear outfitter and as much a social and athletic 
organization as it is a commercial enterprise" (Ehmann and Klanten 2013,90) with the ambitious goal of "mak[ing] cycling the most popular sport in the world". ${ }^{2}$ Rapha was founded in 2004 as a start-up, started a co-operation with the leading British pro-cycling Team Sky in 2013 and was bought by Walmart for 200 million GBP in the summer of 2017 (The Guardian, August 7, 2017). Today its product range and marketing strategy of embedded storytelling addresses commuters, adventurers, as well as sportive cyclists of all sorts and abilities (cf. Glover 2018).

However, in Berlin, novice riders who ride along in expensive clothes, are referred to as "Rapha boys", or similar derogatory terms, by some. These riders, who wear all the right brands and ride expensive bikes, but aren't considered as "natural" members to the scene, are held responsible for culturally appropriating symbols and practices from more serious riders. "Rapha boys" thus stand for the stereotype of inexperienced and often incompetent riders, who solely bought into the lifestyle without truly understanding it. As pretenders are trying to catch up, the "real" riders are already taking it a step further in their distinction: weighing their cereal or slices of bread to make sure they stick to the calory intake exactly right for them; using nutritional supplements or even illegal doping; fine-tuning their training schedule and having their bike fitted by a professional, which can cost several hundred euros; and of course, ride in even the most uninviting weather conditions and regardless of their friends' or families' plans — just because they identify as cyclists, and that is what proper cyclists do.

While the symbolic and material aspects can be copied and tend to enter the mainstream easily, the embodied and lived aspects become more and more refined:

\footnotetext{
${ }^{12}$ https://www.rapha.cc/it/en/stories/riding-is-the-answer
} 
skill, knowledge, commitment, suffering, body cult and sports addiction are dominant in the scene in ways that cannot be justified any longer within the framework of a normal hobby or even amateur sports. Instead, one's identity becomes completely absorbed by bike-related obsessions.

\section{Media Representations: Blogs, Magazines, Books, Videos and Movies}

In recent years, countless numbers of books, blogs, print-magazines, or movies with a focus on urban cycling have been published. Additionally, photographs of cyclists and bicycles have almost become an independent genre on the internet. Furthermore, you will find thousands of short videos on content-sharing platforms like Youtube or Vimeo about urban cycling and commuting, bicycle messengers, alley cats and illegal races, stunts, hacks or tricks, which have contributed to the genre of the "digital bicycle film" (cf. Bennett 2019, $174 \mathrm{ff}$.). Christoph Schulz (2015) suggests, that this has to do with two separate developments: (1) As high-quality audiovisual equipment has been getting cheaper, cyclists more and more became their own filmmakers, documenting their cycling-related lifestyle; (2) Professional filmmakers - in their role as cultural seismographs — have identified cycling and cycle culture as a rising topic.

Providing evidence for the second argument are current mainstream movies. Take the Hollywood movie Premium Rush for example: it is about a bicycle messenger who accidentally gets involved in a crime case and is chased around New York City by cars, riding on his fixed-gear bike, showing off stunts and deviant riding. Also see Tomb Raider from 2018, in which the extensive opening scene shows an inspired by alleycats type of bike messengers' race. While in the 1986 movie Quicksilver the figure of the bicycle messenger illustrates the social decay of a former successful banker, 25-30 years later in Premium Rush and Lara Croft the bicycle messenger eventually becomes the 
successful hero, with the bicycle as his powerful tool that is equivalent to the fast car prominent in most action movies.

\section{Discussion: The Symbolic Revaluation of the Bicycle}

"If a style is really to catch on, if it is to become genuinely popular, it must say the right things in the right way at the right time. It must anticipate or encapsulate a mood, a moment.” - Hebdige 1979, 122

My research leads me to the hypothesis that the bicycle is still a very heterogenous object, but it is becoming more and more a key symbol of popular urban culture, acting as a symbol of lifestyle, status and distinction. Exemplarily, I showed that the fixed-gear bicycle has left a professional and subcultural context and was implemented into urban popular culture, showing tendencies of commercialisation, specialisation and standardisation. While the fixed-gear scene in Berlin is already declining, road and gravel cycling already became popular and much more consumerist alternatives for many sport cyclists, newcomers and hipsters.

Other representations from various fields - media, accessories, social events, cycling shops, fashion and advertising — show a focus on aesthetics, design and lifestyle combined with a specific functionality that often originates from messenger subculture, fixed-gear scene or road biking. Therefore, city and sport cycling in Berlin these days seems to be a lot about cycling in style. Importantly, my research suggests, that these developments have not been flanked by cycling policy, administration or cycling initiatives in Berlin, but instead, have developed in parallel from subcultural, sportive, as well as hedonistic and commercial interest. These constantly add new attributes to the bicycle, making the bicycle and cycling more interesting for late-modern consumer cultures and lifestyle politics (cf. Furness 2010; Greif 2010; Soper 2008; Featherstone 2007). 
In this logic, it may also open new opportunities as cycling might also reach new target groups, users and potential. Considering classical social-psychological motives, one can say that the symbolic incentive of using bicycles is increasing in an urban context. Alternatively, speaking with Jean Baudrillard (1968), the bicycle is significantly gaining sign value, catching up to the car as status symbol and object of lifestyle and distinction - showing a symbolic revaluation of the bicycle. This might challenge the domination of automobility in its cultural foundations and may led way to shape new urban mobility cultures based on velomobility.

Having said that, this symbolic revaluation is based on social mechanisms of difference, consumerism and exclusivity, raising questions of space, social equality and cycling inclusivity itself. Concerning Berlin, the observations largely apply to inner-city neighbourhoods and become almost irrelevant in certain outskirts, being in line with the fundamental critique on bicycles being a tool for individualism, urban gentrification und neoliberalism as framed by Richard Florida's (2005) notion of the bicycle as a signifier of the creative class (cf. Stehlin 2019). Additionally, my observations took place in the context of a privileged white, mainly male, urban middle class. This largely excludes critical feminists or postcolonial perspectives and raises questions of social exclusiveness and cultural uniformity. Some researchers and even riders see the cultural practices described above as one of the main problems to cycling inclusivity and cycling promotion, especially when it comes to reaching women, children, the elderly, socially excluded, people with disabilities, "invisible cyclists" or migrants in their velomobility and sport interest (cf. Lugo 2018; Lam 2018; Lubitow 2016; Hoffmann 2016; Aldred et al. 2016).

Due to this cultural revaluation, some regular cyclists as well as potential cyclists may not identify themselves with this kind of exclusive, lifestyle, consumption 
and sport oriented bicycling culture and might have problems getting in due to cultural, social and economic barriers. This criticism has to be taken very seriously and means, that cycling needs to be diversified and more trans- and interdisciplinary promoted and regulated, not only in traffic planning, mobility research, city planning and health promotion, but also in medial representations and cultural production, bike industry and especially the field of sports.

\section{Acknowledgements:}

This work was kindly supported by the Chair of Integrated Transport Planning at Technische Universität Berlin. I would like to thank my supervisor Prof. Dr. Oliver Schwedes, my $\mathrm{PhD}$ colleagues and the reviewers for their critical examinations and Svenja Paulsen for proofreading, lengthy discussions and thoughtful editing.

\section{Literature}

Aldred, Rachel, James Woodcock, and Anna Goodman. 2016. Does More Cycling Mean More Diversity in Cycling? Transport Reviews 36: 28-44.

Baudrillard, Jean. 1968. The System of Objects. London: Verso Books.

Bennett, Bruce. 2019. Cycling and Cinema. London: Goldsmiths Press.

Bourdieu, Pierre. 1984. Distinction: A Social Critique of the Judgment of Taste. Cambrige, MA: Harvard Press.

Borgstedt, Silke, Franziska Jurczok, and Tim Gensheimer. 2019. Fahrrad-Monitor Deutschland 2019. Ergebnisse einer repräsentativen Online-Befragung. Heidleberg und Berlin: Sinus Marktund Sozialforschung GmbH.

Breidenstein, Georg, Stefan Hirschauer, Herbert Kalkhoff, and Boris Nieswand. 2015.

Ethnografie. Die Praxis der Feldforschung. Konstanz und München: UVK Verlagsgesellschaft.

Clifford, James, and George Marcus. 1986. Writing Culture. The Poetics and Politics of Writing Ethnography. University of California Press, Berkeley et al.

Cox, Peter. 2019. Cycling. A Sociology of Vélomobility. London and New York: Routledge. 
Cox, Peter. 2015. Cycling Cultures. Chester: University of Chester Press.

Denzin, Norman K. 2014. Interpretative Autoethnography. Los Angeles et al.: Sage Publications.

Eichler, Roman. 2017. The Resistance of Fun: Fixed-Gear Cycling in Urban Public Spaces. Space and Culture 20 (2): 239-254.

Ehmann, Sven, and Robert Klanten. 2013. Velo 2nd Gear: Bicycle Culture and Style. Berlin: Die Gestalten Verlag.

Ferrero-Regis, Tiziana. 2016. "Twenty-first century dandyism: fancy Lycra ${ }^{\circledR}$ on two wheels." Annals of Leisure Research 21 (1): 95-112.

Florida, Richard. 2005. Cities and the Creative Class. New York: Routledge.

Featherstone, Mike. 2007. Consumer Culture and Postmodernism. Los Angeles et al.: Sage Publications.

Fincham, Ben. 2006. "Bicycle messengers and the road to freedom." The Sociological Review 54: 208-222.

Furness, Zack. 2010. One Less Car. Bicycling and the Politics of Automobility. Philadelphia: Temple University Press.

Gatersleben, Brigitta. 2013. "Psychological Motives for Car Use." Chap. 6 in Handbook of Sustainable Travel. Dodrecht: Springer.

Gelder, Ken and Sarah Thornton. 1997. The Subcultures Reader. New York / London: Routledge.

Glover, Catherine. 2018. Rapha and its embedded storytelling. Journal of Fashion Marketing and Management: An International Journal 22 (1): 17-34.

Goffman, Erwin. 1951. Symbols of Class Status. The British Journal of Sociology 2 (4): 294304.

Greif, Mark, Kathreen Ross, and Dayna Tortorici. 2010. What Was the Hipster?: A Sociological Investigation. New York: $\mathrm{n}+1$ Foundation.

Grossberg, Lawrence, Cary Nelson and Paula Treichler. 1992. Cultural Studies. New York / London: Routledge.

Hammersley, Martyn, and Paul Atkinson. 2007. Ethnography: Principles in practice. London: Routledge.

Hebdige, Dick. 1979. Subculture - the meaning of style. London: Routledge.

Heinen, Eva, Bert van Wee, and Kees Maat. 2010. "Commuting by bicycle: An overview of the literature." Transport reviews 30 (1): 59-96. 
Hoffmann, Melody L. 2016. Bike Lanes Are White Lanes. Lincoln: University of Nebraska Press.

Hoor, Maximilian. 2020. "Mobilitätskulturen. Über die Notwendigkeit einer kulturellen Perspektive der Verkehrsplanung." IVP Discussion Paper 14 (2020/1).

Horton, Dave, and John Parkin. 2012. "Towards a Revolution in Cycling." Chap. 12 in Cycling and Sustainability. London: Emerald Group Publishing Limited.

Horton, Dave, Paul Rosen, and Peter Cox. 2007. "Introduction." Chap. 1 in Cycling and Society. Hampshire: Ashgate Publishing Limited.

Horton, Dave. 2009. "Social Movements and the Bicycle." Paper presented at the conference Alternative Futures and Popular Protest, Manchester, April 19-21.

Hutchinson, Michael. 2017. Re:Cyclists: 200 Years on two wheels. London and New York: Bloomsbury.

Kidder, Jeffrey L. 2011. Urban Flow: Bike Messengers and the City. Ithaca, NY: Cornell University Press.

King, Ted. 2020. "Gravel 2020 - A Look at American Gravel Racing and Beyond" Presentation at Digital World Bike 31.03.2020.

Lam, Tiffany. 2018. Cycling London: An Intersectional Feminist Perspective. Masterarbeit. LSE Cities, London.

Lamnek, Siegfried. 2010. Qualitative Sozialforschung: Lehrbuch. Weinheim/Basel: Beltz Verlag.

Lessing, Hans-Erhard. 2017. Das Fahrrad: Eine Kulturgeschichte. Stuttgart: Klett-Cotta.

Lindner, Rolf. 2010. Die Stunde der Cultural Studies. Wien: Universitätsverlag Wien.

Lubitow, Amy. 2016. "Barriers to Routine Cycling for Women and Minorities in Portland, Oregon. " Presented at Cycling \& Society Symposium at Lancaster University, September 2016.

Lugo, Adonia. 2018. Bicycle / Race. Transportation, Culture, \& Resistance. Microcosm Publishing, Portland.

Manderscheid, Katharina. 2014. "The Movement Problem, the Car and Post-Fordist Mobility: Automobility as Dispositif and Mode of Regulation." Special Issue: Mobilities and Foucault, Mobilities 9 (4): 604-626.

MobG BE. 2018. Berliner Mobilitätsgesetz. Berlin: Land Berlin. http://gesetze.berlin.de/jportal/?quelle=jlink\&query=MobG+BE\&psml=bsbeprod.psml\&max $=$ tr ue

Muggleton, David. 2000. Inside Subculture: The Postmodern Meaning of Style. New York: Berg. Nobis, Claudia. 2019. Mobilität in Deutschland-MiD Analysen zum Radverkehr und 
Fußverkehr. Bonn / Berlin: Bundesministeriums für Verkehr und digitale Infrastruktur. www.mobilität-in-deutschland.de

Potter, Patrick. 2010. 42x12: The Cult of Fixed. Berkeley, CA: Gingko Press Inc.

Simmel, Georg. 1957. "Fashion.” The American Journal of Sociology 62 (6): 541-558.

Steg, Linda, Charles Vlek, and Goos Slotegraaf. 2001. "Instrumental-reasoned and symbolicaffective motives for using a motor car." Transportation Research Part F 4: 151-169.

Thornton, Sarah. 1995. Club Culture: Music, Media and Subcultural Capital. Cambridge: Polity Press.

Schiermer, Bjørn. 2013. "Late-modern hipsters: New tendencies in popular culture." Acta Sociologica 57 (2): 167-181.

Schulz, Christoph. 2015. VELOBerlin Film Award - How online films encounter bicycle culture worldwide. Talk at VELO CITY 2015. TAM08 - Bicycle and Media.

Schweer, Sebastian. 2014. Skateboarding - Zwischen urbaner Rebellion und neoliberalem Selbstentwurf. Bielefeld: Transcript.

Sheldrick, Alistair, James Evans, and Gabriele Schliwa. 2016. "Policy learning and sustainable urban transitions: Mobilising Berlin's cycling renaissance.” Urban Studies 54 (12).

Smethurst, Paul. 2015. The Bicycle - Towards A Global History. Palgrave Macmillan: Basingstoke.

Soper, Kate. 2008. "Alternative Hedonism, Cultural Theory and the Role of Aesthetic Revisioning." Cultural Studies 22 (5): 567-587.

Spradley, James P. 2016. The Ethnographic Interview. Long Grove, IL: Waveland Press, Inc.

Stehlin, John. 2019. Cyclespaces of the unequal city. Bicycle infrastructure and uneven development. University of Minnessota Press, Minneapolis, MN.

Strauss, Anselm, and Juliet Corbin. 1990. Basics of Qualitative Research: Grounded Theory Procedures and Techniques. Los Angeles et al.: Sage Publications.

Urry, John. 2004. The 'System' of Automobility. Theory, Culture \& Society 21 (4-5): 25-39.

Velominati. 2014. The Rules: The Way of the Cycling Disciple. New York: W. W. Norton \& Company.

Vivanco, Luis. 2013. Reconsidering the Bicycle: An Anthropological Perspective on a New (Old) Thing. London and New York: Routledge.

von Schneidemesser, Dirk, Jeremias Herberg, and Dorota Stasiak. 2018. "Wissen auf die Straße - ko-kreative Verkehrspolitik jenseits der "Knowledge-Action-Gap"." Chap 6 in Das Wissen der Nachhaltigkeit. Herausforderungen zwischen Forschung und Beratung. München: oekom Verlag.

Wehr, Kevin. 2009. Hermes on Two Wheels: The Sociology of Bicycle Messengers. Lanham: 
University Press of America.

Williams, Raymond. 1981. Culture. Glasgow: Fontana.

Williams, Raymond. 1961. The Long Revolution. London: Chatto \& Windus 